\title{
MULHERES PROFESSORAS: UM JEITO DE SER E PERCEBER-SE MULHER
}

\author{
Indiamara Hummler Oda
}

ste estudo se inspirou nos trabalhos que evidenciam o recorte

Mulher e discute a mulher como uma construção social. Nesse sentido, segue uma linha de discussão, isto é, a idéia de que existem mulheres em todas as sociedades e dentro de uma mesma sociedade, a exemplo da nossa, onde estão presentes as classes e camadas sociais. É o realce a assertiva de Simone de Beauvoir (1980), quando argumenta "que o ser humano indicado como feminino é uma produção da civilização em seu conjunto", cuja compreensão deve considerar a sociedade e a capacidade de sua cultura. O "fato biológico", portanto, só adquire sentido em um contexto social. Desse modo, dizer que uma pessoa não nasce mulher, torna-se mulher, como diz a autora, é defender o ponto de vista de que a identidade feminina é sempre um produto de um conjunto de determinações e processos.

Nas sociedades contemporâneas, a compreensão da identidade feminina e a sua expressão, em formas múltiplas, implica em considerar posição de classe, religião, questão de pertencer a um grupo étnico, biografia e trajetórias pessoais, rede de parentesco, entre outros. (Cavalcanti \& Heilborn, 1979).

Seguindo esta trilha de pensamento, procurei estudar um grupo específico de mulheres, evidenciando determinações, tais como: o "habitus" profissional, a trajetória pessoal, a vivência no mundo da casa, a fim de fazer uma "leitura" a respeito da identidade feminina, revelada por mulheres profissionais, voltadas ao ensino universitário, área de Ciências Sociais, da Universidade Estadual de Londrina, em uma cidade de porte médio, no Norte do Paraná - Londrina. Em outras 
palavras, a intenção foi apreender as concepções destas mulheres sobre o feminino, partindo do princípio de que existem miríades de identidades femininas e que elas se expressam através da variedade de experiências vivenciadas, enquanto mulher, dentro de um contexto sócio-cultural.

O interesse em estudar este tema "mulher" fundamenta-se na sua relevância pela produção acadêmica, que tem procurado discutir indagações, possibilitando respostas constantes, por meio de diferentes pesquisas. Nesse sentido, evidencia-se a perspectiva antropológica, uma vez que a Antropologia vem correspondendo às questões colocadas pelo mundo contemporâneo, em relação a este tema, e é uma ciência que tem permitido a compreensão do feminino em diferentes sociedades no tempo e no espaço. O meu recorte empírico - mulheres universitárias -é ainda pouco estudado, comparativamente a outros. Dessa maneira, assumindo essa idéia das múltiplas identidades femininas, empenheime em descortinar a identidade de determinadas mulheres que vivenciam as experiências de um mundo público específico, o universitário, e também do mundo privado, percebendo como estas práticas atuam na concepção que estas mulheres têm do feminino.

É um trabalho que retrata um universo "microscópico", um grupo de mulheres, sem desconsiderar as relações deste com um contexto mais amplo e com o movimento feminista. Revela uma leitura de personagens da sociedade contemporânea, em especial, a brasileira, que procura evidenciar a diversidade, contemplando heterogeneidade cultural e a complexidade social, mostrando as várias possibilidades de ser e perceber-se mulher.

A possibilidade de desenvolver uma pesquisa com este grupo de mulheres professoras tem suas raízes na convivência com profissionais voltadas a um mundo público específico, o cotidiano universitário, no momento de minha graduação em Ciências Sociais. Durante esse tempo, estabeleci alianças para o exercício da vocação e laços de amizade. Ao mesmo tempo, preocupada com o tema "mulher", inquietava-me com suas maneiras de ser, de se conceberem e conceberem o mundo, o que me levou a descortinar as suas concepções.

Para o estudo, foram consideradas conversas informais e realizadas seis entrevistas com docentes das diferente áreas do curso de Ciências sociais: duas sociólogas, duas cientistas políticas, uma 
antropóloga e uma docente da cultura brasileira .A maioria fez a graduação nesse curso, seguido da Especialização, do Mestrado e Doutorado, em áreas básicas que constituem a ciência da sociedade. Realizada de março a maio de 1997, a pesquisa visou um grupo de mulheres, com idade que variou entre 40 a 55 anos, todas casadas e possuindo filhos. A maioria fixou residência em Londrina, mora em casa própria, embora suas trajetórias de vida revelassem passagens e residências em outros lugares. Com relação ao aspecto econômico, a fonte de renda, independente dos maridos, provém das atividades acadêmicas, numa variante entre 20 a 30 salários mínimos. Apesar das especificidades que norteiam suas trajetórias, assim como a leitura que têm do mundo - a qual reflete, de algum modo, a área de conhecimento em que se especializaram -, o "habitus" profissional de cientista social impõe uma reflexão constante do meio no qual estão inseridas. Assim, entre essas mulheres evidenciouse um ponto convergente, isto é, uma concepção elaborada do pensamento sobre a sociedade em que vivem, bem como do lugar que nela ocupam. Levando em conta esses aspectos, as observações pautamse nas relações que essas mulheres estabelecem com os mundos público e privado, problematizando o papel feminino tradicional e sugerindo as concepções particulares de um grupo específico da sociedade inclusiva. Em outros termos, mulheres com atividades não especificamente domésticas e com experiências em um mundo público particular.

\section{Algumas notas para discussão}

A complexidade dessa discussão sobre Mulher remete-nos à concretude do fato que é universal, ou seja, a assimetria de papéis masculinos e femininos que, em cada contexto específico, revela graus diversos de dominância masculina. Nesse sentido, Eunice Durham, ao refletir sobre os papéis masculinos e femininos, em diferentes sociedades, argumenta que "a guerra e a política são em todos os lugares, atividades essencialmente masculinas, das quais as mulheres quando participam, o fazem de modo secundário, complementar ou substantivo. Entretanto, o cuidado com as crianças e sua socialização são sempre de competência feminina." (Durham, 1983, p.16 ). Para a maioria das outras 
sociedades, àquelas que se constituíram no objeto tradicional da Antropologia, a oposição homem/mulher recorta, uniformemente, todas as esferas da vida social, e a distinção entre público e privado não se dá em termos de uma separação radical. Existem, muitas vezes, formas diversas de trabalhos coletivos com participação diferenciada de homens e mulheres, fazendo com que haja uma complementaridade necessária entre papéis femininos e masculinos, permeando tanto a vida pública quanto a vida privada. (Rosaldo, e Lamphere, 1979).

Em sociedades como a nossa, mesmo com as transformações que ocorreram na organização do trabalho, provocadas pelo capitalismo, acabaram por inserir a mulher no mercado do trabalho impessoal, ocasionando mudanças na posição feminina; são comuns, no imaginário sobre a mulher, concepções que atribuem padrões de comportamentos voltados às atividades domésticas e ao cuidado com os filhos.

Essa ideologia cultural, - que afirma a identidade feminina como imperativo biológico e social da reprodução - acaba por ocultar a capacidade da mulher em assumir outras atividades, além daquelas que se apresentam na esfera privada. Entretanto, a emergência de uma contestação explícita da assimetria da divisão sexual do trabalho, bem como da dominância masculina, é, então, um fenômeno específico da nossa sociedade e se relaciona com o desenvolvimento do capitalismo.

O que se apresenta em um contexto social como é o nosso, de um lado, a tendência a uma reformulação da divisão sexual do trabalho na esfera doméstica, influenciada pelo modelo do igualitarismo individualista, criado na esfera pública; de outro, a dissolução da aparência de naturalidade no tocante aos papéis femininos como derivados de funções biológicas para, então, percebê-los como uma criação humana mutável. São referências às possibilidades que envolvem a flexibilidade na ideologia de gênero, no sentido de superar a demarcação definitiva daquilo que se subentende como espaço majoritário masculino. (Durham,1984).

Nesse sentido, o significado do que é uma posição feminina envolve a trajetória de mulheres e a apreensão de códigos de um novo universo que vêm conquistando. A década de 60, por exemplo, simbolizou a questão política através de movimentos feministas que fluíram no Brasil e no mundo, justificando o desenvolvimento do individualismo e a questão da natureza - distinção do mundo público 
e do mundo privado. (Salem, 1980).

A discussão da mundialização do sistema capitalista possibilita perceber que ela não acarreta, somente, a homogeneidade nos processos sociais, ao contrário, a incorporação desigual no sistema mundial e de fatores internos à própria lógica do capitalismo tem reposto e renovado as diferenças entre grupos. Diferenças estas que se tornam um dos elementos mais importantes na criação de valores coletivos e na construção de legitimidades sociais. É o caso das mulheres, quando denunciam as crenças que justificam a sua sujeição. A convergência dessas idéias, na literatura recente em direção aos processos culturais, é indício seguro da atualidade da cultura, no discurso social contemporâneo. Nestes termos, “(...) o campo da cultura tornou-se uma das principais arenas da disputa política e da produção da legitimidade". (Montero, 1991, p.119).

Considerando tais constatações, o entendimento de um universo do mundo contemporâneo, seguindo a tradição etnográfica e recolocando-a em um novo contexto, a interpretação desse grupo de mulheres docentes, universitárias, trouxe à tona o significado que elas atribuem às suas ações, voltadas ao mundo público, bem como as mudanças que essa participação supõe no mundo doméstico. Em outros termos, procurou-se compreender como se dá a relação sexo, trabalho, reprodução, e, portanto, a concepção do feminino para este grupo particular.

Seguindo esse objetivo, ao retratar a realidade do mundo doméstico dessas mulheres, evidenciou-se um espaço social que assinalou um grupo fechado com fronteiras e limites bem definidos. Os depoimentos no tocante ao relacionamento entre os membros da família e seus respectivos papéis permitiram detectar de que forma os atores desempenham esses papéis na estrutura familiar, bem como o jeito de ser em família.

\section{O Mundo doméstico: o reconhecimento pessoal}

"Nós somos providas geneticamente de outras forças que os homens não têm, e que nos remeteriam a fazer qualquer coisa em proteção das 
crias. Isso aí eu acho que é a marca do universo feminino"

"Existem coisas que tiram de nós por sermos mulheres, mas acabam dando outras. Nós somos mais amorosas, mais sensitivas, mais doces :coisas que deveriam ser do Ser humano."

A concepção particular de que é preciso haver conscientização na divisão sexual do trabalho, apareceu de forma explícita nos depoimentos das mulheres investigadas. Foi possível perceber que o auxílio do marido nas tarefas domésticas corresponde a uma colaboração. A administração, o cuidado, as responsabilidades com o mundo doméstico são, enfim, atribuídos à mulher. $O$ homem não consegue visualizar essas responsabilidades como sendo suas também. Neste sentido, "o que existe é uma sociedade masculina, com muitas coisas mal elaboradas em relação à mulher". A evidência é que "não podemos tratar isso como um problema biológico porque é social. Os homens não fazem porque ninguém se preocupa em treiná-lo para fazer isso. O homem tem que se (re) socializar." As críticas voltadas a uma sociedade machista colocam em evidência a preservação de valores tradicionais que persistem através do processo de reprodução social. Em outras palavras, a educação social é substanciada pela distinção de tarefas, consideradas pela sociedade, cabíveis ao homem, bem como àquelas que são estabelecidas para o feminino.

Na experiência do cotidiano , "os homens ajudam as mulheres, eles compartilham do mundo da casa, mas sempre nessa situação de ajudar". Retrata-se aqui a incorporação da participação em esferas prioritárias, atribuídas ao universo masculino e feminino, sobre as quais a interferência é estabelecida e exercida, de forma desigual, para os dois sexos. Isso implica, segundo o grupo de mulheres em questão, que "se estabeleçam entre homens e mulheres novos princípios através dos quais, as atividades do mundo da casa sejam, também, incorporadas como responsabilidades masculinas". Vislumbra-se aqui a mudança de comportamentos que são vistos como cíclicos.

Entretanto, incluso a essas colocações, atribui-se outro aspecto, a ocupação de uma determinada posição social. Deste modo, o conceito de papel refere-se, também, ao desempenho efetivo, levado a cabo por um ator no exercício de sua função. A idéia de comportamento não 
pode ser entendida apenas pela prática expressiva do ator, pelos dados observáveis de seu comportamento; deve sim, pelas suas representações, isto é, pela maneira particular que o ator explica e retrata suas práticas segundo sua própria lógica. (Salem,1980). O exercício da análise de papéis contém, então, uma perspectiva de elaboração de desempenho a partir das representações. Por meio desse processo, surgem possibilidades de se criarem, desprezarem, revisarem ou confirmarem padrões de comportamentos que constituem papéis masculino e feminino. Revela-se, assim, a necessidade de se conceber um espaço à interpretação subjetiva, dando condições para compreender como se promovem definições e redefinições contínuas de sua situação e da situação daqueles com os quais a mulher convive. Nestes termos, é importante voltar a atenção às práticas e representações culturais, considerando que discursos, de um lado, e ações, de outro, não são realidades que se opõem nem que operam, distorcendo uma a outra: seriam antes formas diferentes, mas complementares de expressão de um mesmo universo simbólico que só pode ser apreendido como sistema abstrato, todavia que se manifesta através da especificidade de cada situação concreta. (Magnani,1984).

Torna-se importante ressaltar que o fato de essas mulheres se referirem a novas formas de pensar, a divisão sexual do trabalho não significa , necessariamente, a negação de papéis. Em outros termos, embora continuem a exercer funções domésticas, apesar das transformações que ocorreram na sociedade e, a referência aqui é ao universo feminino, esse aspecto não assume uma postura de modo a denegrir a identidade feminina.

As mudanças que elas reivindicam no tocante a (re)socializar sob novas perspectivas, apontam para uma divisão sexual do trabalho, completamente, desvinculada de um ajustamento mecânico que, até então, tem acentuado, em demasia, o significado ideológico, ou grandemente doutrinário, da fixação de papel de gêneros. Dirimindo, dessa forma, o impacto daquelas atividades concretas da vida, através das quais as experiências típicas e determinantes de homens e mulheres são formadas, influenciando as percepções e interpretações que homens e mulheres têm do mundo e de seu lugar nele.(Markus, 1994).

Ao considerar a idéia de redefinições de comportamentos 
relacionadas com os respectivos papéis masculino e feminino, é importante perceber o processo de aprendizagem de papéis socialmente determinados. Trata-se da socialização primária que é definida como uma ampla e consistente introdução de um indivíduo, no mundo objetivo, de uma sociedade ou um setor dela, cujas funções e representações, socialmente prescritas, são subjetivamente incorporadas. Nisso consiste o treinamento diferencial a que estão submetidos os filhos e as filhas. (Berger \& Luckmann, 1974). No que concerne a esse aspecto, as mulheres entrevistadas apresentaram divergências em suas posições. De um lado, são as concepções que evidenciaram o caráter de garantir a continuidade dos valores e regras tradicionais por meio da socialização primária, ou seja, as respectivas diferenças que cada gênero tende a assumir a partir dessa educação. Nesse sentido, apontaram as coordenadas que estabelecem as funções que, determinadas pela cultura, são cabíveis à mulher: cuidado com a casa, com os filhos e com o marido: Para elas, "a mãe era dona de casa, e daquelas donas de casa que nunca tiveram empregada. E desde aos dez anos de idade a gente já era era iniciada aos serviços domésticos também." Por sua vez, de outro lado, outras entrevistas demonstraram que certas diferenças, na forma de socializar, foram marcantes, pois abriram espaços, isto é, condições de visualizar outras aptidões que não se restringem, apenas, às tarefas domésticas. Explicam assim, " os meus pais tinham uma meta na vida deles, que era estudar e transformar as filhas em profissionais independentes". Tais constatações permitem a reflexão de que existem visões de socialização primária que podem ser consideradas como alternativas e até contraditórias, levando em conta as pressões culturais. $\mathrm{O}$ contato com outros sistemas simbólicos, quer dizer, com significativos que coexistem com os padrões considerados normais pela sociedade, possibilita negar a validade de valores e regras tradicionais transmitidas por meio da socialização primária, como guias indiscutíveis de ações.

Entretanto, é inconcebível imaginar uma ruptura total com a visão de mundo e "os modelos de ações". Reconhecer a existência de uma ampliação de oportunidades educacionais não significa supor que as funções prescritas socialmente são, em todos os sentidos, contestadas. Em outros termos, o que se propõe é que, vinculada à 
distribuição de tradicionais tarefas, socialmente, determinadas, pode haver uma série de atribuições socializadoras, que combinem estas tarefas com outras. Acrescentando, desse modo, ao processo de aprendizagem, destinado ao sexo feminino, outros valores, senão aqueles que se limitam, apenas, ao mundo da casa.

A reflexão sobre as imposições substanciadas por valores, normas e regras, estende-se, ainda, a uma questão muito polêmica: trata-se do poder e da autoridade no mundo privado. Esse aspecto envolve princípios, diante dos quais a figura do homem detém posição determinante, exercendo poder e autoridade incontestes e absolutos no seio do espaço social doméstico.

Com base nos argumentos das docentes, revelou-se aspiração ao poder e à autoridade, compartilhados no mundo da casa, embora, a maioria das respostas, confirmasse a supremacia do poder e da autoridade masculina, sinalizando a cristalização do padrão cultural e sua alocação ao espaço doméstico. A mulher pode ter poder e autoridade no mundo doméstico, entretanto, existem circunstâncias que envolvem esse poder: "um poder que é considerado como 'mixuruca', 'minimizado'; um poder que passa pela necessidade da conscientização do homem sobre a importância da mulher na estrutura familiar. O que se expressa aqui é um poder exercitado, no cotidiano da casa, pelas mulheres, porém, com a dificuldade do homem em aceitá-lo, uma vez que no processo de aprendizagem sobre o que é ser homem, os companheiros destas mulheres também internalizaram um modelo de comportamento. Assim, o que se expressa é uma assimetria entre as práticas e as representações, insinuando, contudo, rupturas nos modelos de comportamentos. Os valores sociais provocam na mulher um sentimento íntimo de desvalorização e de falta de confiança própria; ao contrário dos homens que, sustentados pela tradição, revestem-se de liderança, independência. $\mathrm{O}$ fato de o poder e a autoridade serem construídos em torno da hierarquia masculina, acarreta a injuriosa posição em que a mulher é colocada, ou seja, um ser carente no sentido de tomar decisões, enfrentar riscos, assumir liderança e ter poder.(Bardwick, 1981).

Sabemos que essas imposições, apesar de prescritas, socialmente, não correspondem à atual realidade. Embora ignorado tradicionalmente, o uso do poder e da autoridade pode ser acessível às 
mulheres, assim como o é aos homens. Nesse sentido, apesar de todas as sociedades, realmente, conhecidas revelarem a dominância masculina, ainda que tal dominância varie de grau, certa dominação não presume o total esmagamento da personagem que se encontra na posição de subordinada. Ao contrário, nessa relação integra-se, de maneira constitutiva, a necessidade de preservação da figura subalterna. Sua subalternidade, contudo, não significa a ausência absoluta do poder. Há de se considerar que nos dois pólos da relação existe poder, ainda que em doses tremendamente desiguais.(Saffioti, 1992).

As representações das professoras trazem a possibilidade de se repensar neste modelo imposição / homem e aceitação / mulher, estabelecendo uma nova relação, em comum acordo, entre os sexos. São inovações de preceitos que substanciam uma relação a dois. As entrevistas expuseram os princípios que sustentam uma relação conjugal estável. Nesse aspecto, os constituintes necessários para a construção de uma vida conjugal equilibrada, estão presentes em valores, como exemplos, afetividade, sensibilidade, delicadeza, paciência, os quais não devem ser caracterizados somente na identidade feminina, mas, também, devem estar inseridos no universo masculino. Nisso consiste o fato de que o homem precisa ser feminino, sem que, necessariamente, tenha jeito feminino. São princípios que pretendem diluir o imaginário que caracteriza o universo masculino e feminino em relação às qualidades simbólicas, exclusivas do homem e da mulher, assim como se expressam no relacionamento do casal. É preciso, no entanto, perceber que "o alcance desse ideal conjugal depende de constante reflexão, cultivo e investimento", e as mulheres afirmam que "não existe nada pronto, é uma luta cotidiana para alcançar ideais juntos, onde o casal se pensa como estando em constante estado de reestruturação". É uma situação vivenciada por essas mulheres, na construção da vida a dois, em que, apesar do modelo apreendido, o fato de elas trabalharem, inclusive, fora do espaço doméstico, provoca um redimensionamento das concepções, quanto às qualidades atribuídas ao homem e à mulher, vislumbrando-se um "modelo para".

A relação que se estabelece com os filhos está inclusa nessa discussão; e segundo os depoimentos, esta relação, instituída entre as gerações, é uma continuidade de valores que foram assimilados 
pela mãe. Em outros termos, as entrevistadas argumentam que os limites determinados na educação de seus filhos, foram, de certa forma, uma reprodução dos mesmos limites impostos a essas mulheres. No entanto, a maior preocupação que se evidenciou foi a de um certo receio no sentido de que os filhos se sintam na obrigação de satisfazer às vontades que se estabelecem através das expectativas da mãe. Existe, aí, todo um cuidado entre os valores transformados em normas e valores que surgem como opção. Para que haja uma escolha no intuito de seguir esse ou aquele caminho, é preciso que existam instruções que auxiliem a definição do que queremos ser, sem as restrições que nos levam ao que devemos ser.

Diante destas colocações, depreende-se que o mundo privado para essas mulheres assume extrema importância. O significado atribuído a esse mundo reflete-se através da necessidade imprescindível que se volta à questão existencial, isto é, não deve ser reconhecido, apenas, como um lugar de diferenças de papéis que determinam funções para este ou aquele gênero. Da mesma forma, não pode ser entendido como um espaço vazio. O mundo privado, ou melhor, o mundo da família é cheio de emoções, é um lugar de mútua necessidade do outro. É um universo enriquecido pelas preocupações, tristezas, alegrias, companheirismo, solidariedade, motivações. Nesse sentido, "a família não é um simples lugar de reprodução, mas daquilo que, na vida cotidiana, escapa do sentido." (Pacífico, 1986, p.155). De uma outra forma, a valorização do espaço da casa revela um reconhecimento pessoal, um espaço em que se realizam projetos de vida, envolvendo uma convivência social profunda, onde ser mãe, esposa e docente, ganham uma dimensão exclusiva, por meio das redes de parentesco e amizade.

\section{O significado do mundo público: reconhecimento, prestígio, conquista .}

Em contraposição ao domínio privado, percebido como um espaço aberto às relações familiares, à afetividade, o espaço público retrata outros códigos, ou seja, está aberto ao legalismo jurídico, ao mercado, ao progresso individualista. (Da Matta, 1985). Nesses termos, 
é também neste universo, que nossas entrevistadas estão presentes. Desse espaço, falam e se explicam, explicam os outros e o mundo. Assim, a identidade dessas mulheres tem a referência de um universo público: a Universidade. De acordo com os depoimentos, a experiência de vivenciar o mundo acadêmico foi definida, por um lado, como um universo de construção e transferência de conhecimentos, por outro, o ensino e a pesquisa constituem-se no processo de ensinar e aprender; há também, um espaço de "competição", de "mecanismos, de poder e de fama", de "veneno", "um mundo esquizofrênico, ocasionando relações interpessoais tensas":

Para caracterizar o mundo acadêmico como um mundo particular, segue-se a trilha de Bourdieu que considera a ciência como um campo social, isto é, enquanto um sistema de relações objetivas entre posições adquiridas. Desse modo, o campo científico é o lugar de jogo, de uma luta concorrencial. O que está em jogo, especificamente, nessa luta, é o monopólio da autoridade científica, definida como capacidade técnica e poder social. (Bourdieu, 1983).

Quanto à questão de desempenhar a função de intelectual na sociedade, bem como no tocante aos seus projetos, uma delas percebese intelectual no sentido de lidar com o mundo das idéias, outras mostraram a preocupação em exercer bem o papel de professoras, enfatizando a necessidade de viver em outros universos, sem perder de vista as regras do campo da ciência Também, ficou evidente, no depoimento de uma professora, a intenção de fazer um trabalho de retorno imediato à comunidade.

Com a exceção de uma delas, as entrevistadas não se consideram, enquanto intelectuais. Entretanto, ao buscarem compreender a sociedade em suas várias dimensões, em que pesem as especificidades dos ângulos de análises das diferentes áreas do conhecimento que compõem as Ciências Sociais - foram preparadas por centros de ensino e pesquisa (instituições) reconhecidos, dentro do campo científico. Portanto, essas mulheres lidam com saberes especializados para explicarem a sociedade. Estão envolvidas com as ciências interpretativas em que criam teorias. Seus discursos retratam uma preocupação com a dissociação entre o "fazer e saber" que ocorreu num momento preciso da história e se aprofundou no capitalismo, como resultado de sua organização interna. 
Nestes termos, o trabalho intelectual e o trabalho manual são pensados e vivenciados nas sociedades industriais, como realidades distintas e distantes umas das outras. Ao tratarem com diversos universos de pesquisas, deparam-se com variados valores e concepções de mundo vigentes numa sociedade complexa e diferenciada. Desse modo, fundamentadas em referenciais teóricos, entendem e transmitem aos seus alunos sobre práticas culturais e visões de mundo numa perspectiva plural e dinâmica. Também estão conscientes de que seus objetos de pesquisa são, inclusive, sujeitos e têm saberes específicos. Sabem da necessidade em articular o saber da academia com o saber dos grupos pesquisados.

Assim, considerando os saberes especializados, enquanto constitutivos do universo de trabalho dessas mulheres e, também, a visão ampliada que têm de intelectuais, seguimos a orientação gramsciana que discute sobre o desempenho da função social da categoria profissional dos intelectuais, destacando os intelectuais "orgânicos" e os intelectuais "tradicionais", bem como a intervenção intelectual como atributo da atividade humana.

Como explica Gramsci (1978), cada grupo social, nascendo no terreno originário de uma função essencial no mundo da produção econômica, cria-se para si, ao mesmo tempo, de um mesmo modo orgânico, uma ou mais camadas intelectuais que dão homogeneidade e consciência da própria função, não apenas no mundo, mas também, no mundo social e político. Cada grupo social "essencial", surgido na história, a partir da estrutura econômica anterior e como expressão de desenvolvimento desta estrutura, encontrou categorias intelectuais preexistentes, as quais apareciam como representantes de uma continuidade histórica que não se interrompeu, nem mesmo pelas mais complicadas e radicais modificações das formas sociais e políticas.

Prossegue o autor, enfatizando que para a acepção de intelectuais, o critério de distinção, no que é intrínseco às atividades intelectuais, deveria ser buscado no conjunto do sistema de relações, no qual estas atividades se encontram, no conjunto geral das relações sociais. Dessa maneira, o operário não se caracteriza, especificamente, pelo trabalho manual, porém, por esse trabalho em determinadas relações sociais. Em qualquer trabalho físico, existe um mínimo de qualificação técnica, isto 
é, um mínimo de atividade intelectual criadora.

Frente a tais colocações, todos os homens são intelectuais, mas nem todos desempenham a função de intelectual. Dito de outro modo... "todo homem fora de sua profissão, desenvolve um mínimo de atividade intelectual qualquer, ou seja, é um filósofo, um artista, um homem de gosto, participa de uma concepção de mundo; possui uma linha consciente de conduta moral, contribui assim para manter ou modificar uma concepção de mundo, isto é, para promover novas maneiras de pensar" (Gramsci, 1978, p.7-8)

Historicamente, formam-se categorias especializadas para o exercício da função intelectual. O desenvolvimento alcançado pela atividade e pela organização escolar, nas sociedades que surgiram do mundo medieval, indica a importância assumida no mundo moderno pelas categorias e funções intelectuais. Este é o resultado das instituições escolares de graus diversos que visam promover a chamada a "alta cultura" em todos os campos da ciência e da técnica. A escola é um instrumento para elaborar os intelectuais de diversos níveis. (Gramsci,1978)

Finalmente, o que propõe Gramsci é a participação ativa dos intelectuais na vida prática como construtores, organizadores, permanentes persuasores e não simplesmente oradores. Sendo assim, ao afirmar a necessidade do contato entre os intelectuais e os simples, não o faz para restringir a atividade científica e preservar a unidade no nível inferior das massas, mas para construir um bloco intelectual, moral capaz de tornar possível o progresso intelectual das massas e não apenas de pequenos grupos intelectuais.(Gramsci,1978)

Considerando ainda essa discussão, evidencia-se uma noção de conhecimento, voltada às dimensões da razão e da emoção. A questão vincula-se ao fato de essas mulheres difundirem ao mundo público algumas experiências do mundo doméstico. Ao contrário da dicotomia que se estabelece pelo social, elas apontam uma relação de extensão e não de oposição: ora o trabalho da rua se estende ao mundo da casa, ora este se estende ao mundo do trabalho.

Percebe-se, então, um equilíbrio entre o racional e o emocional. $\mathrm{O}$ fato de exercerem uma posição no mundo público não significa que devam desvencilhar-se do jeito de serem mulheres: o maternal. Isso pode ser constatado, quando algumas entrevistadas consideram assumir 
a postura de "mãezona" com os alunos .

Pressupõe-se, assim, que os seus comportamentos não parecem ser condicionados pelas obrigações que, de uma forma ou de outra, o trabalho estabelece. O que vem à tona é um sentimento de satisfação pelo que fazem. As suas funções são mediadas pelas relações de afetividade, preocupação, respeito e responsabilidade que se firmam entre professor e aluno.

Nesse sentido, refletem-se a própria identidade feminina e a sua ambivalência com relação ao trabalho, quer dizer, ao processo de socialização do privado que se introjeta no espaço público, resultando na complementaridade que acompanha a trabalhadora mãe, ligada à trabalhadora mulher.

Com essa reflexão sobre o mundo público destas docentes, buscou-se retratar um aspecto que está inter-relacionado a vários fatores, ou seja, a luta pela igualdade, a independência financeira, vinculada à liberdade, à duplicidade de esforços, ao poder e à autoridade. Pode-se considerar que todos esses fatores estão ligados às discriminações que envolvem o mundo do trabalho.

Os depoimentos obtidos revelaram que a condição feminina passou a sofrer uma contradição fundamental. A inclusão simultânea da mulher nas duas esferas, a pública e a privada, proporcionou a percepção de sua luta pela igualdade, enquanto indivíduo no mercado de trabalho, e de sua desigualdade, enquanto mulher, confinada na sua esfera doméstica da produção. (Durham, 1983).

A questão da independência financeira reporta-nos à consciência de que a independência econômica, vinculada ao trabalho fora do lar, nem sempre pode ser considerada como uma luta para a libertação. A valorização do ganho ou do lucro pode vir marcada por uma dupla jornada de trabalho, de esforços, que ameaçam o mérito concedido à independência econômica. Diante disso, reconhecemos que a independência financeira pode vir a libertar, de alguma forma, o que não significa conceber essa independência como uma liberdade plena. Acima de tudo, somos seres sociais e, dessa forma, estamos presos a uma rede de regras e comportamentos que são impostos e impedem a realização da liberdade no seu todo.(Kuhner, 1977).

No tocante à relação do poder e da autoridade, Salem expõe que 
mais que um atributo pessoal, o poder é pensado como um processo dinâmico e interativo. (Salem, 1980). A veracidade desta colocação, relacionada à posição das docentes, revela que a mulher se obriga a utilizar das mesmas armas que os homens utilizam para conquistar algum respeito frente à autoridade e ao poder masculino. O uso da gentileza, de argumentações e, até mesmo de um tratamento especial, que não seja interpretado como um relacionamento íntimo, não são suficientes, em alguns casos, para conter a postura dominante masculina.

De certo modo, a atuação feminina no mundo público não reivindica a igualdade entre homens e mulheres. Sabe-se que essa igualdade poderia resultar no esmagamento dos valores femininos. Ao invés de se pensar na oposição público e privado, cujas limitações, através de princípios sociais e culturais, determinam o que é feminino e o que é masculino, as perspectivas de construções de novos valores deveriam, sim, pautar-se na complementaridade, ou seja, modificar os pressupostos sexistas, a fim de que homens e mulheres compartilhassem concepções de vida juntos.

\section{Percebendo-se mulher...}

A percepção destas mulheres está vinculada, quer ao mundo doméstico, quer ao universo público dos quais participam. Nestes termos, apesar de desempenharem a dupla jornada de trabalho, elas valorizam o mundo conquistado, explicando. "hoje, eu acho que não dá mais para a mulher atuar só no mundo privado, fica muito fechado.” Assim, suas falas revelam uma concepção de si e de outras mulheres, pois é importante para elas "reconhecer-se mulher mais completa, que tem mais o que dizer, que vê o mundo de uma forma menos dolorosa", uma vez que sentem lentamente o reconhecimento e o prestígio por aquilo que executam, no cotidiano e por seus projetos que vão além do mundo doméstico. Vislumbram uma mudança nos padrões que até então definiram os papéis masculino e feminino. Dessa maneira, elas se sentem responsáveis pela construção de um universo mais amplo, visto, na maioria das vezes, como uma construção do homem. Na forma de perceber as diferentes situações enfrentadas, entendem que a convivência com 
outros universos permitiu um "treinamento" e, portanto, a percepção e a aceitação de que existem diferentes maneiras de resolução para os mesmos problemas. Assim, "conseguimos um certo tipo de equilíbrio, maturidade, que permite olhar as coisas com muita relativização; as relações, as pessoas, os comportamentos."

As mulheres professoras revelam - apesar de expressarem comportamentos e visões que retratam a continuidade do padrão cultural, a exemplo do processo de socialização que impôs qualidades simbólicas ao papel da mulher - também as subversões, demostrando a redefinição do modelo, tanto pelas práticas, o modo como agem, quanto pelas representações, como a visão e consciência do lugar que ocupam na sociedade. Deste modo, elas provocam mudanças no mundo da casa, ao discutirem com seus companheiros o papel que cabe a ambos, considerando um processo lento para a dissolução dominação/homem, subordinação/mulher. Também, suas falas exprimiram a dissolução de idéias internalizadas por elas próprias, enquanto mulheres. Algumas delas revelaram obterem uma renda igual ou superior ao marido, um fato que elas tiveram de administrar, inclusive para não deixarem inverter a relação dominação/mulher, subordinação/homem. O que acontece é que "muitas mulheres, hoje, têm um renda superior ou igual ao homem, que, muitas vezes, não sabe como é o nosso trabalho. Vivemos em mundos de trabalho muito diversos. É bom porque enriquece as conversas, mas também a gente teve que ir ajustando arestas. A gente teve que acertar muitos pontos."

Estas mulheres sabem muito bem manipular os códigos da casa, trazendo-os para o mundo público. Se em algumas ocasiões, elas tiveram de usar as estratégias femininas para vencer os obstáculos na relação homem/mulher, no mundo público, muitás vezes, em situações de mando, elas transferiram estes códigos, pois "as mulheres sabem lidar com o mundo da casa e com os homens, eles exercem o papel de chefes, é cultural. No mundo público não é ruim usar das sutilezas, elas funcionam". Nestes termos, estas mulheres sabem das ambiguiidades que estão presentes, quando se defrontam com homens no mundo do trabalho. Na verdade, "eles reconhecem o nosso potencial, mas nos vêem também invadindo o seu pedaço, talvez pensado por muitos como mais masculino, principalmente quando se trata de assumir determinadas 
posições administrativas, aquelas que fogem da sala de aula."

Além de serem mulheres que se percebem como educadoras, consideram-se preparadas intelectualmente para falar e ver o mundo. Também, dizem que "pelo fato de estarem envolvidas com a universidade, conseguem aprender mais as relações políticas, e se desprendem do 'mundinho' particular." Porém, não deixam de criticar a “impessoalidade e o individualismo" que marcam o mundo público do qual participam e com evidência falam do mundo da casa, "um espaço de solidariedade, de experiências coletivas". Assim, o jeito de viver está dividido entre o convívio familiar e o cotidiano da academia. Neste último, dedicam-se à pesquisa e à arte de ensinar e isto "as faz fortes, apaixonadas pela vida e pelo momento em que vivem".

Enquanto mulheres, têm as sua vaidades e excentricidades, a maioria pratica um esporte, como tênis, ginástica localizada, hidroginástica, caminhadas, "para aliviar as tensões do dia-a-dia, e, igualmente, para ampliar relacionamentos e cuidar do corpo e da saúde." Percebem-se bonitas, privilegiando a auto- construção de mulher, a forma como vêem e discutem o mundo, o jeito como se vestem e se produzem, atravessando os modelos de beleza, reconhecidos e divulgados pela mídia ,mostrando que beleza é relativa a valores específicos.

Diante deste quadro, a retratação de um estilo de vida, voltado a um mundo público particular, trouxe à tona, também, a valorização do mundo doméstico e da família. Em outras palavras, através do cotidiano do trabalho e da casa, essas mulheres falaram de si, sobre si e do mundo feminino. Os depoimentos evidenciaram mulheres conscientes do lugar que ocupam na sociedade, já que expressaram sobre o aprendizado de ser mulher e, também, a respeito da incorporação de novos padrões de comportamento, quando confrontados com novas situações. Assim, valores novos podem conviver com antigos, comportamentos e atitudes podem permanecer, porém, vão-se rompendo.

Esse grupo de mulheres e suas atividades permitiu mostrar como, em casos específicos, mulheres vão dissolvendo as relações, em termos da caracterização dominação - homem/mundo público, e subordinaçãomulher/mundo privado. Permitiu entender as propostas destas mulheres para se tratar de comportamentos e atitudes como atributos do ser 
humano, deixando de privilegiar os universos masculino e feminino.

Enfim, estas mulheres são conscientes dos seus limites e dos seus alcances e, considerando as suas percepções, foi possível apreender um pouco deste universo. Nestes termos, compreender o mundo feminino é perceber, ao mesmo tempo, padrões mais amplos, contudo, a redefinição desses padrões, revelando sobre a "aceitação" e a "oposição" dos valores da sociedade inclusiva. Nesse sentido, é importante voltar os olhos à relação entre as práticas culturais e as concepções das mulheres, evidenciando o que fazem e o que pensam, a fim de desvendar o que as faz semelhantes às outras mulheres, no entanto, diferentes, mostrando, por isso, identidades particulares e a existência de "mulheres".

\section{Notas}

${ }^{1}$ Os depoimentos presentes no artigo são das mulheres professoras. Estão inclusas, entre aspas, as falas das entrevistadas em partes do contexto como um todo.

\section{Referências Bibliográficas}

BARDWICK, Judith M. Mulher, Sociedade, Transição. In: Feminilidade $e$ Masculinidade: Mudança de percepções. São Paulo: Difel. 1981.

BEAUVOIR, Simone. In : O segundo sexo : 1. Fatos e Mitos; 2. A experiência vivida. Rio de Janeiro : Nova Fronteira. 2 v. 1980.

BERGER, Peter \& LUCKMANN, Thomas. L. A Construção social da realidade: Tratado de sociologia do conhecimento. Petropólis: Vozes. 1974.

BOURDIEU, Pierre. Gostos de classes e estilos de vida. In: ORTIZ, Renato . Pierre Bourdieu. São Paulo: Ática, 1983.

MATTA, Roberto da. Espaço: Casa, rua e outro mundo: o caso do Brasil. In: A casa e a rua-espaço, cidadania, mulher e morte no Brasil . São Paulo: Brasiliense, p. $25-54,1985$.

DURHAM, Eunice R. Família e reprodução humana. In: FRANCHETTO, Bruna; CAVALCANTI, Maria Laura J. C. ; HEILBORN, Luiza (Org.) Perspectivas 
antropológicas da mulher. Rio de Janeiro: Paz e Terra, 1979

Cultura e ideologia. In: Dados. Revista de Ciências Soci-

ais. Rio de Janeiro: Campus. v.27, 3.1, p.71-79.

GRAMSCI, Antônio. Os intelectuais e a organização da cultura. Rio de Janeiro: Civilização Brasileira, 1978,

KUHNER, Maria Helena. O Desafio Atual da Mulher. Rio de Janeiro: Francisco Alves, 1977.

MAGNANI, José Guilherme. Discurso e representação, ou de como os Baloma de Kiriwina podem reencarnar-se nas pesquisas atuais. In: CARDOSO, Ruth C.L. (Org.) A aventura antropológica: teoria e pesquisa. Rio de Janeiro: Paz e Terra, 1986.

MONTERO, Paula .Reflexões sobre uma Antropologia das sociedades complexas. In: Revista de Antropologia. São Paulo. Departamento de Antropologia. FFLCH/ USP, v.34,p.103 a 130, 1991.

PACÍFICO, Mariella. Operárias numa região sul da Itália. In: KARTCHEVSKY, André et al. $O$ Sexo do Trabalho. Rio de Janeiro: Paz e Terra,1986.

ROSALDO, Michelle Zimbalist \& LAMPHERE, Louise. A mulher, a cultura e a sociedade. Rio de Janeiro: Paz e Terra.,1979.

SAFFIOTI, Heleieth I. B. Rearticulando Gênero e Classe Social. In: COSTA, Albertina de Oliveira; BRUSCHINI, Cristina (orgs. ). Uma questão de gênero. Rio de Janeiro: Rosa dos Tempos / São Paulo: Fundação Carlos Chagas ,1992.

SALEM, Tânia . Conflito, poder e negociação na família: a questão geracional. In: Dados. Revista de Ciências Sociais. Rio de Janeiro: Campus, v. 23, n. 02, p. $185-$ 200, 1980 


\section{Resumo}

O presente artigo tem a preocupação de revelar as concepções de um grupo de mulheres a respeito do universo feminino, considerando as suas práticas sociais, isto é, contemplando a inserção em um mundo público específico, a Universidade. Também a ligação com o mundo doméstico e suas trajetórias pessoais. Pretende, assim, demonstrar que a Mulher é uma construção social e que a identidade feminina está fundamentada num conjunto de determinações, reforçando a assertiva que considera a existência de múltiplas identidades femininas, sem desconsiderar que em suas experiências se encontram elementos recorrentes e interesses comuns .

Palavras-chave: mulheres; representações; práticas sociais; mundo privado; mundo público.

\section{Abstract}

This article is concerned with disclosing the conceptions of a group of women in a feminine universe, considering their social practices, that is, observing the insertion in a specific public world, the University. It also analyses the connection with the household world as well as their personal path. Thus, this work intends to demonstrate that the woman is a social construction and the feminine identity is wellfounded in a set of determinations reinforcing the existence of multiple feminine identities, without ignoring that in their expiriences they meet recurring elements and commom interests.

Key Words: women; representations; social practices; private world; public world. 